\title{
El guionista como traductor: construcción imaginaria de un texto efímero
}

\author{
The scriptwriter as a translator: imaginary construction of an ephemeral text
}

Rubén Dittus (ruben.dittus@ucentral.cl) Facultad de Economía, Gobierno y Comunicaciones, Universidad Central de Chile (Santiago, Chile) ORCID: 0000-0002-7613-1643

\begin{abstract}
This essay seeks to epistemologically feed the figure of the scriptwriter as a singular translator. It is a creator who does not translate but let translate from an exercise of symbolic imagination where the cosmic, the oneiric and the poetic are expressed in a type of language. Using a reverse technique, he opposes the thesis of the untranslatable. The control of interpretive gaps would be, rather, the requirement that allows the content of messages from one grammar system to be adapted to another, each with its own codes and rules, but using the figure of a semi-open work. We approach the role of scriptwriter-translator from a double conceptual anchorage. On the one hand, the idea that translation is a form, thesis developed by Walter Benjamin in his essay "The task of the translator". On the other hand, the paradigm described by Paul Ricoeur in "On translation", in which he develops the practical alternative of fidelity versus treason. In both authors the existence of an original is supposed. The translator maintains a close relationship with that original. In the theory of the script, since the translation exists, it is necessary that it be possible.
\end{abstract}

Key words: scriptwriter, translator, reality, language, imaginary.

\section{Resumen}

Este ensayo busca alimentar epistemológicamente la figura del guionista como un traductor singular. Se trata de un creador que no traduce, sino que deja traducir desde un particular ejercicio de imaginación simbólica donde lo cósmico, lo onírico y lo poético se expresan en un tipo de lenguaje. Usando una técnica inversa, se opone a la tesis de lo intraducible. El control de los vacíos interpretativos sería, más bien, el requisito que permite adaptar el contenido de mensajes de un sistema gramatical a otro, cada uno con sus propios códigos y reglas, pero usando la figura de una obra semiabierta. Abordamos el rol de guionistatraductor desde un doble anclaje conceptual. Por un lado, la idea de que la traducción es una forma, tesis que desarrolla Walter Benjamin en su ensayo "La tarea del traductor". Por otro, el paradigma descrito por Paul Ricoeur en "Sobre la traducción", en el cual desarrolla la alternativa práctica de fidelidad versus traición. En ambos autores se supone la existencia de un original. El traductor mantiene una relación próxima con ese original. En la teoría del guion, puesto que la traducción existe, es necesario que sea posible.

Palabras clave: guionista, traductor, realidad, lenguaje, imaginario. 


\section{Introducción}

Dicho en palabras simples, el guionista es aquella persona que escribe guiones. Por su parte, el guion es cualquier texto más o menos acabado que pretende ser otra cosa: una película, una serie de televisión, un videoclip o un cómic. Es una partitura, confeccionada para que otros la ejecuten. Puede ser un músico, un cineasta o un dibujante. Su naturaleza lo convierte en un documento transitorio, que se construye para ser eliminado, dando paso a un texto definitivo y único. La particularidad está aquí: es un texto que nace para ser traducido. En su concepción lleva implícita la marca indeleble de un largo viaje. Es ese rasgo el que convierte al guionista en un traductor. Imagina y escribe con un lenguaje que será necesariamente traducido.

La traducción es un ejercicio intelectual que se sostiene porque hay dos lenguas que potencialmente pueden decir lo mismo, pero, con otras palabras. En cualquier caso, es la acción o el acto de traducir. Gastón Sironi nos facilita una síntesis etimológica de la palabra traducir, a la cual confluyen -dice- varios ríos: conducir, trasladar, hacer cruzar o pasar de un lado a otro. Es decir, "la idea de viaje está en esos orígenes: alguien que viaja y encuentra a un otro que habla en otra lengua, en otra melodía" (Sironi 2015:153). Paul Ricoeur en Sobre la traducción la define como pretender decir lo mismo de dos maneras diferentes, o decir lo mismo, pero de otro modo. Walter Benjamin en La tarea del traductor dice que la traducción del lenguaje poético es una forma, por lo que la traducibilidad de ciertas obras debería ser esencial. Aunque también reconoce que no es necesario que los buenos traductores sean buenos poetas. Para Henri Meschonnic en Ética y política del traducir existe una equivalencia entre traducir e interpretar, aun en una misma lengua, porque la traducción es un problema del lenguaje, no de la lengua. De ese modo, cuando se traduce según el signo, la única expectativa es la del sentido, porque el signo no conoce otra cosa. O como se pregunta Alfonso Reyes a propósito del imposible problema de la traducción: “¿quién no ha oído hablar alguna vez de las cosas que solo se pueden decir en tal o cual lengua?" (Reyes 1983:133).

Umberto Eco con su ironía de costumbre se preguntaba en el ya clásico Decir casi lo mismo, que tenemos muchos problemas para explicar este enunciado que origina el título de su libro. Primero, es problemático establecer qué significa "decir lo mismo". En segundo lugar, porque no sabemos qué es el "lo", o sea, ante un texto no sabemos lo que debemos traducir. Y, por último, porque en algunos casos abrigamos serias dudas sobre lo que quiere decir "decir". Esto lleva a Eco a elaborar un nuevo concepto: "traducir quiere decir entender tanto el sistema interno de una lengua como la estructura de un texto en esa lengua" (Eco 2010:18).

Pero también podemos entender la traducción como un proceso creativo. Al descartar la opción del calco, traducir asume la categoría de mímesis, tal como fue definida por Aristóteles. Lo representado o imitado no solo es el objeto de partida sino todo su complejo proceso creador. De modo que, si el escritor de ficción es un fingidor, el traductor finge dos veces, el del primer autor y el de su interpretación de esa ficción. Estas dificultades conceptuales se explican porque lo más difícil del acto de traducir es identificar es qué es lo que un texto quiere transmitir, y cómo transmitirlo. O sea, en la traducción está inherente la comunicabilidad de un texto original, virgen de ser leído desde una lengua extranjera. Todo surge por el deseo de fidelidad. En teoría, todo autor está en permanente búsqueda del traductor fiel. Se advierte, entonces, una natural tensión entre la fidelidad y la traición. En otros términos, un texto original espera nunca ser traicionado por un mal traductor.

¿Cómo se explica esto? En opinión de Ricoeur, el acto de traducir (o su posibilidad) lleva consigo una pulsión. Recordemos que toda pulsión es considerada una fuerza que impulsa al sujeto a llevar a cabo una 
acción con el fin de satisfacer una tensión interna. En teoría, la pulsión se dirige a un único fin preciso: suprimir o calmar ese estado de tensión. Para lograr este fin, la pulsión se sirve de un objeto, el que no necesariamente es uno preciso. En la traducción, la pulsión se explica por la insatisfacción de quien traduce y de la obra que se traduce. Ello no es sino la búsqueda de la traducción perfecta o la confección del "texto magnífico", un deseo que se expresa en un afán cosmopolita y una universalidad que busca suprimir la distancia entre lo propio y lo ajeno.

En efecto, aquí en la traducción se unen dos dimensiones: lo extranjero (la obra, el autor, su lengua) y el destinatario de la obra traducida. Siguiendo a Ricoeur, traducir es como servir a dos amos: al extranjero en su obra y al lector en su deseo de apropiación, debido a una pretensión de autosuficiencia (se rechaza cualquier forma de mediación de lo extranjero) y que proviene del etnocentrismo lingüístico y la hegemonía cultural. Esa búsqueda de la traducción perfecta u omnitraducción tiene un efecto de resistencia, que actúa como un motor implícito. La resistencia de traducir se explica porque hay un rechazo solapado de lo extranjero por parte de la lengua receptora.

Y esto tiene un sustento lingüístico: todo texto tiene zonas de intraductibilidad que estarían diseminadas debido a campos semánticos que se superponen o sintaxis no equivalentes. Es decir, los giros idiomáticos no son capaces de transmitir los mismos legados culturales. A juicio de Ricoeur, es debido a ese complejo de heterogeneidad que el texto extranjero tiene resistencia a la traducción. Se trataría de una especie de sospecha de traición, como algo inherente al acto de traducir; y que proviene del autor del texto original. Ricoeur cita a Antoine Berman, para quien existen dos modalidades de resistencia, lo que convierte al traductor en un actor ambivalente. Por un lado, el texto se resiste a ser traducido; y por otro, la lengua receptora de la traducción mira con sospecha ese acto intrusivo, forzando la lengua a cargar con el lastre de lo extranjero, y alejando a la cultura que la cobija de sus convicciones lingüísticas.

Umbero Eco es explícito en esta materia. Nos dice: "El concepto de fidelidad tiene que ver con la convicción de que la traducción es una de las formas de la interpretación y que debe apuntar siempre, aun partiendo de la sensibilidad y de la cultura del lector, a reencontrarse no ya con la intención del autor, sino con la intención del texto, con lo que el texto dice o sugiere con relación a la lengua en que se expresa y al contexto cultural en que ha nacido" (Eco 2010:23).

Complementando la definición de fidelidad que propone Eco, a juicio de Ricoeur, la imposibilidad de la traducción absoluta trae consigo la felicidad de traducir. El filósofo la llama "hospitalidad lingüística". Es aceptar la distancia entre la adecuación y la equivalencia. Implica asumir la irreductibilidad de lo propio y lo extranjero como un binomio inseparable del acto de traducir. Ello significa que toda traducción presenta unos márgenes de infidelidad con respecto a un núcleo de sentido de presunta fidelidad. Fidelidad e infidelidad (o traición). Ambas, caras de una misma moneda. Para alcanzar ese estado, el acto de traducir lleva consigo como corolario un acto posterior de retraducción, una especie de ejercicio de bilingüismo, que garantizaría tal felicidad, "donde el placer de habitar la lengua del otro es compensado por el placer de recibir en la propia casa la palabra del extranjero" (Ricoeur 2005:28). Como dice Eco, traducir es establecer la flexibilidad del texto original, la cual depende de una serie de criterios que hay que negociar preliminarmente.

En los términos propuestos por Walter Benjamin en La tarea del traductor, el signo característico de una mala traducción es aquella que se propusiera solo desempeñar la función de intermediario. No se puede hablar de traducción inexacta de un contenido no esencial, que deje de lado al lector. El efecto es que la traducción (el texto segundo) no es esencial para la obra original (el texto primero), pero mantiene con 
ésta una relación íntima. Debemos reconocer, siguiendo el análisis hecho por Paul de Man (La tarea del traductor de Walter Benjamin), que el clásico ensayo de Benjamin al que hacemos alusión, muestra al poeta como una figura casi sacra, que hace eco de un lenguaje casi sagrado, por lo que la tarea del traductor alcanza niveles más allá de lo presupuestado ante los ojos de la modernidad. Esto pone al autor alemán, al menos, en una postura contradictoria. De hecho, una de las razones por las que Benjamin toma al traductor y no al poeta es que el traductor, por definición falla. Es la acusación que el traductor nunca podrá estar a la altura del texto original, y muy lejos del poeta.

Más cerca de lo profano, en el proceso de guionismo, esta relación íntima entre el original y la traducción, es vital. No se observan estas diferencias creativas que observa Benjamin en la literatura poética. La proyección de la primera depende de la configuración de la segunda. Es por lo que el guionista -el auténtico primer autor del espacio poético que será visto en imágenes- garantiza en el tejido del guion todos aquellos recursos que serán fielmente traducibles por el equipo de realización visual o audiovisual, develando siempre los misterios ocultos del texto primero. La vida del original alcanza en el texto segundo su expansión en vida y póstuma más vasta y siempre renovada que cualquier otra creación.

Descartando la teoría del calco, la presente reflexión parte de la premisa de que no es posible acceder a una realidad objetiva, por lo que se descarta la posibilidad de que el mismo sentido sea expresado idénticamente por dos lenguajes distintos. Es negar la presencia de la exactitud. Intencionalmente dejamos fuera de la reflexión el guion adaptado, considerado por la teoría como un claro ejemplo de reescritura, con fórmulas y códigos precisos que se escapan a la tarea de construcción de un guion original.

\section{El guion como texto primero}

A diferencia de cualquier otro texto, el guion nace para ser traducido. Para ser convertido en otro lenguaje: dibujo, imágenes, movimiento o sonido. Su naturaleza lo convierte desde el origen en una forma efímera, circunstancial y pasajera, que busca un destino definitivo: la película, la serie de TV, el spot comercial, el cómic (Dittus. El guionista chileno). En cualquier caso, se trata de un ejercicio de construcción imaginaria. ¿Cómo funciona? Ya sabemos que imaginar es un recurso mental concebido como el resultado de nuestra condición de seres sociables. Imaginamos porque vivimos en sociedad. Es un viaje que se lleva a cabo en el propio lenguaje. Es una acción metalingüística. Así como interpretar es traducir o comprender es traducir (George Steiner. Después de Babel), imaginar es crear. Siguiendo a Bachelart (La poética del espacio), solo la fenomenología puede ayudarnos a restituir la subjetividad de las imágenes y a medir la amplitud, la fuerza, el sentido de la transubjetividad de la imagen. Es decir, la imagen poética que el guionista forma en la conciencia es esencialmente variable. Al igual que el poeta, en la novedad de sus imágenes es siempre origen del lenguaje.

Gilbert Durand nos recuerda que la conciencia tiene dos maneras de representarse el mundo. Una directa, a través de la cual la cosa se presenta directamente ante nuestros sentidos más básicos; y una indirecta, cuando la cosa se presenta a través de la imaginación. En este último caso, el objeto ausente se "representa" (Durand 2000:10) ante la conciencia a través de una imagen. En la mayoría de los casos, esa imagen adquiere forma de signo, inserto en un sistema de economía conceptual. El guionista hace uso de un conjunto de signos lingüísticos que le dan sentido a un relato futuro, ello porque el significado que se configura en su conciencia es imposible de presentar. Solo es factible a través de un tipo particular de signo: el símbolo. Se trata del recurso que mejor representa algo desconocido, difícil de explicar con palabras. Como éstas no dan el ancho para el sentido que se construye en su conciencia, los nuevos símbolos que le darán forma a las ideas del guionista conducen lo sensible de lo representado en primera 
instancia en el guion, pero reconociendo en éste su naturaleza como texto con un conjunto de significados inaccesibles.

Un ejemplo de esto es lo que explica Jacques Lacan sobre el arte en relación con la Cosa. Slavoj Zizek lo explica en un ensayo referido sobre la Cosa venida del interior en el cine del director y guionista ruso Andrei Tarkovski. Para el filósofo esloveno, el arte lacaniano se estructura siempre alrededor del vacío central de la cosa imposible o traumática. Es el caso, dice Zizek en Lacrimae rerum, del monstruo tipo Alien en las películas de ciencia ficción. Se trata de una Cosa que aparece marcada como parte de nosotros mismos proyectada sobre la realidad. La intrusión de la Cosa parece traer un alivio, cancelando el horror vacío de un infinito que carece de forma y fondo. El guionista debe entregar, al menos, bosquejos de la Cosa. El propósito de ésta debe quedar instalado en el texto primero, dando acceso a los nuevos formatos que tendrá.

Es esa inaccesibilidad la que el guionista-traductor debe manejar, para que el sentido de lo que imaginó se mantenga intacto. Las garantías de que las segundas representaciones serán fieles al sentido primero se encuentran en la forma como los seres humanos construimos realidad en la conciencia. Siguiendo a Cornelius Castoriadis, imaginar la sociedad implica crearla de algún modo. Es decir, "psique y lo históricosocial son irreductibles el uno al otro" (1998:41), lo que permite una adecuada batería de códigos interpretables. De algún modo, la creación de lo social en la psique permite que creadores y receptores de mensajes hagan uso de la universalidad en variadas formas de traducción, donde los límites están en lo imaginable. Finitos, por cierto.

Es la conciencia la que otorga esos márgenes de lo imaginable. De hecho, el problema de la conciencia es de larga data. La ausencia de una definición consensuada es la mejor prueba de que, incluso la psicología o las neurociencias, presentan abismos infranqueables. Históricamente se le ha situado como algo opuesto a la objetividad. Es decir, la conciencia como hábitat de las subjetividades del alma. De cualquier modo, el habla común instala el problema de la conciencia como el lugar donde surge la capacidad de distinguir el "yo" de los "otros". La identidad del self se manifiesta como una prueba de que estamos capacitados para desarrollar, entre otras tareas, exigencias como narradores o intérpretes de experiencias ficticias. La conciencia ayudaría a establecer límites precisos entre lo real y lo representado. Es el lugar donde las neuronas espejo permiten desarrollar capacidades imitativas y de aprendizaje de códigos secundarios al habla materna. Formatos como el cine o la televisión han sido grandes mecanismos para conseguir adaptarnos al entorno, siendo el guionista uno de los primeros narradores que debe adaptarse a través del uso de lo imaginado.

Es por ello que la tarea del guionista-traductor puede asimilarse a un viaje que no termina con su propia autoría. El guionista sabe que su trabajo es el de coautor, pero donde predomina la subjetividad. Este viaje nos muestra al guion como un dispositivo de proyecciones imaginarias que no surgen en el vacío absoluto. Es un artificio donde se objetivan situaciones, sucesos y personajes que, luego, serán representadas e interpretadas. Es un mecanismo que controla el ritmo, la duración y la puesta en escena. Para un lector de guiones, la referencia a una doctrina que lleva el nombre tan a menudo mal entendido de fenomenología, corre el riesgo de permanecer oscura. La imagen, en su simplicidad, no necesita un saber. Como la poesía, es propiedad de una conciencia ingenua y mágica. Sin embargo, la imagen poética no es un riesgo para la traductibilidad del texto original. Al contrario, le da garantías de que la intersubjetividad se lleve a cabo en el proceso de traducción. 
En el campo del guion tampoco es aplicable la tesis de lo intraducible. Según ésta, la fidelidad es la máxima que se busca en la interpretación de un texto original llevado a otra lengua. En atención de ello, no existe traición posible al convertir palabras en imágenes. No hay nada que arriesgar, puesto que lo se traduce es la transformación del significante de un lenguaje a otro. El lenguaje audiovisual es precisamente eso: lenguaje, no lengua.

Esta idea es ya un clásico enunciado formulado en los orígenes de la semiótica del cine por Christian Metz, para quien el cine no es una lengua porque contraviene a tres características importantes del hecho lingüístico. La más importante es que "la imagen es siempre y en primer lugar una imagen: reproduce en toda su literalidad perceptiva el espectáculo significado del cual es significante" (Metz 2002:99). Ello implica que el cine y la imagen escapan a una segunda articulación, como sí ocurre con el sistema de la lengua verbal, tal como lo enseñó el suizo Ferdinand de Saussure. Esto no impide que el cine no pueda decir o narrar algo, pero sin que para ello sea necesario manipular las imágenes como si fuesen palabras.

El guionista trabaja con el proceso inverso que el empleado por el semiólogo de las imágenes, para quien van dirigidos los ensayos de Metz. Aquél (el guionista) sabe de antemano que su creación lingüística debe convertirse tarde o temprano en imágenes, sonidos y movimiento (o viñetas como en el cómic). Para eso, facilita en su concepción, la traducción posible y una identidad de sentido demostrable, no equívoca, para su correcta ejecución. Se observa, necesariamente, en todo guionista auténtico el deseo de traducir, y que va más allá de la mera imposición o utilidad. Es la esencia de su escritura. Desechada una vez que se traduce en otra cosa. Escribe para que otro traduzca su creación. Es decir, es un traductor que no traduce, sino que deja traducir. Usando una técnica inversa, se opone a la tesis de lo intraducible. Los recortes serían, más bien, elementos necesarios que permiten adaptar el contenido de mensajes de un sistema gramatical a otro, cada uno con sus propios códigos y reglas.

En la teoría del guion, puesto que la traducción existe, es necesario que sea posible. Hay, sin embargo, posiciones opuestas al respecto. La historia del cine se ha encargado de entregarnos a dos figuras: Andréi Tarkovski y Raúl Ruiz. Ambos, además de directores, fueron connotados guionistas, pero para sí mismos.

Para el cineasta ruso, la traducción sería imposible si están separadas las funciones de director y guionista: "Si queremos que el guion se pegue a la película, lo escribiremos tal como se vaya a filmar, es decir, plasmaremos con palabras lo que queremos ver en la pantalla. Se trataría del típico guion ilegible" (Tarkovski 2017:83). Ello, porque con frecuencia la escritura de guiones se aleja bastante a su representación cinematográfica. La máxima es la siguiente: no se puede transcribir la imagen fílmica con palabras. Es la razón por la que Tarkovski no podía filmar guiones de otros. Algunos dirán... pésimo traductor. Yo diría, más bien una obsesión por la fidelidad, de pensar el cine de principio a fin. Es lo propio del cine de autor.

En una línea similar, Raúl Ruiz se esmeraría en no trabajar con el guion detallado. Más bien, lo escribía para no someterse a éste. El realizador chileno más destacado en cine diría más de una vez que la poética del cine consistía en diseñar el enigma (la película secreta), que posteriormente debía desentrañar el espectador. Con ese propósito, Ruiz iniciaba con el guion un viaje en el que la construcción de relatos se alejaba del diseño original, por lo cual su labor de traducción se llevaba a cabo en el mismo proceso de filmación y finalizaba en la sala de montaje: "Con dicha metodología Ruiz va más allá, al filmar todo lo que está fuera del guion, tal como trabajan los músicos orientales, que tienen una partitura, para luego tocar todo, menos la propia partitura. Toda una desacralización del guion" (Dittus 2017:197). 
En ambos casos, Ruiz y Tarkovski, se aprecia una concepción particular del trabajo con el texto primero, pues en la práctica no existiría texto segundo. No habría traducción. El trabajo de ambos siempre fue pensado para sí. Los vacíos eran asumidos como una decisión política o estética.

\section{La ley de la traductibilidad}

En la práctica, las exigencias de traductibilidad son hoy día una ley. La especialización de las tareas en la creación, desarrollo, diseño y publicación de textos audiovisuales requiere de escritores que nutran de relatos o conceptos a equipos en los que el texto primero es parte del puntapié inicial para el arte de contar historias, alejadas de la clásica figura de "El narrador", bosquejado magistralmente por Benjamin en el ensayo del mismo nombre. En este nuevo trabajo en equipo, el deseo de perfección con el original, no tienen cabida. La traducción primera (la del mismo guionista) y la posterior son requisito de subsistencia.

Fijémonos en el cómic. Es un arte que combina en un mismo espacio palabra y dibujo, con todas las excepciones posibles para esta regla (podría el dibujo no tener palabras, pero de igual forma fue ideado a partir de una descripción verbal de la viñeta). Es un ejemplo de que la alianza es posible. Por un lado, el buen contador de historias y creador de personajes, pero con pocas o nulas habilidades para el dibujo. Por otro, el dibujante, ilustrador o coloreador, pero con habilidades argumentales en desuso. También los hay quienes relatan y dibujan, pero más de alguna vez el dibujante deberá mostrar la historia de otro. En cualquier caso, tenemos un escritor con la capacidad para pensar en imágenes. Pues de eso se trata. Pensar en imágenes. Dejar que esas descripciones y diálogos sean puestos en un croquis por otro. La historia concebida solo estará completa una vez que esté dibujada. La traductibilidad es requisito. De otro modo, requeriríamos solo de narradores-dibujantes. No siempre los hay, o al menos en abundancia.

Alejándonos del ensayo de Benjamin, donde sacraliza la creación poética, se descarta el deseo de perfección. El guionista tiene la imperiosa labor de integrar elementos para una composición que se debate entre el texto sagrado y el profano. Sagrado, porque expresa un argumento filosófico o moral universal. Profano, porque confecciona una historia que es de uno y es de todos al mismo tiempo, y porque no cierra la posibilidad a futuras nuevas traducciones, bajo la premisa de que "siempre se puede decir lo mismo de otra manera". Es decir, se observa la doble dimensión de autor y traductor del guionista, quien siempre está preparado para traducir lo intraducible.

El guionista no deja nada oculto. Abre el secreto y devela el misterio, para que no quepa duda de que el sentido es tal o cual. Comunica lo poético del texto. Lo deja en la superficie del tejido. Lo indecible, lo incomunicable es contradictorio con la esencia misma de la tarea del guion, ya sea este solo un acotado texto o un detallado conjunto de instrucciones sobre dichos, movimientos, espacios y personajes. Lo esencial del texto primero es lo que precisamente el guion nunca incluirá, ya que ello no puede ser explicado con palabras. Su destino es y será siempre el texto segundo. El guionista se aleja de aquello que Marcel Detienne explica en Comparar lo incomparable. La tesis es clara: "solo se puede comparar lo comparable" (2001:45). Es la extranjeridad absoluta la que impediría comparar dos textos equivalentes, situación que no se logra en el guion, dado su rol como texto efímero (destinado a desaparecer tras la concreción del texto segundo), y, por lo tanto, sin equivalencia con el segundo.

La teoría de la traducción aplicada al guion serviría para poner de relieve la relación íntima que guardan dos lenguajes entre sí: la palabra y la imagen, asumiendo -eso sí- que estos guardan diferencias sustantivas. Sin embargo, también sirve para constatar que la tesis de la exactitud y el parentesco alimentan el 
fantasma de la intraductibilidad, pues esta deja de lado el sentido y se enfoca en el calco. En palabras de Benjamin: "Si es cierto que en la traducción se hace patente el parentesco de los idiomas, conviene añadir que no guarda relación alguna con la vaga semejanza que existe entre la copia y el original. De esto se infiere que el parentesco no implica forzosamente la semejanza" (1971:133).

En efecto, lengua e imagen pueden expresar el mismo sentido, pero ello no significa que sean lenguajes o formas idénticos. De hecho, los efectos en el público serán notorios. En esa diferencia descansa la universalidad del lenguaje cinematográfico, separada de la lógica racional y lineal de la cultura hablada, escrita e impresa. El texto impreso ha sido el mejor propagador de la estructura de la lengua y del racionalismo cartesiano. El guion sigue los caminos de ese orden lógico, secuencial y kantiano. Sus palabras y frases ordenan la imagen poética del creador, caóticamente concebidas. Como dice Jean Epstein (El cine del diablo) refiriéndose al texto impreso, de ese mecanismo esencialmente deductivo solo puede surgir un tejido cargado de deducciones.

Ello no significa que el film como texto segundo no pueda escapar a ese marcado racionalismo, pero su naturaleza inexacta y artística lo libera de pesadas cargas impuestas por el texto primero. Y es que la imagen cinematográfica se presta mal a la esquematización. Se aleja de una arquitectura rigurosa o predecible. Es instintivo, romántico y evocador. Pero el film es, al mismo tiempo, prueba o evidencia. Difícilmente deduce. El cine es psíquico. Sus salas son "laboratorios mentales en los que se concreta un psiquismo colectivo a partir de un haz luminoso" (Morin 2001:179). Se unen, por tanto, dos psiquismos: el de la película y el del espectador. Lo que el primer creador -el guionista- escribe, se transforma en una imagen que cobra vida según los parámetros del realizador, y se diluye en las lecturas de la audiencia. Es esa distancia interpretativa la que obliga a traducir. Es el inicio de una larga espera, donde los actores y el montaje tienen la última palabra.

Imaginemos, por ejemplo, que llega a nuestras manos la clásica escena del beso. Es un guion cinematográfico inédito escrito en nuestra lengua, el español. El texto describe en detalles la acción de los protagonistas. En esta no hay diálogo. La escena dice así: “Por fin, los enamorados tienen el tiempo para mirarse cara a cara, como en una burbuja temporal. En ese momento nada más existe para ellos. El tiempo se detiene. De hecho, el reloj mural deja se sonar (de hacer tic-tac). El espacio es uno solo. Él acaricia el cabello de ella. Ella pone su mano en la mejilla de él. Él se deja acariciar y acercan sus labios. Ella antes de besarlo lo huele y empieza a desabotonar su camisa".

Mientras leemos el guion, nuestra mente se abre a las posibilidades de la imaginación. En el mejor de los casos nuestra respiración de torna irregular, pues el momento nos gusta, nos excita, nos posee. La descripción, sin embargo, deja fuera detalles importantes de la escena, sobre todo para lectores obsesivos. Nada se dice sobre el color de pelo de ambos, o su estatura, tampoco si los zapatos de ella eran rojos o grises. Un experto escritor nos diría que son elementos que quedan fuera de la traducción, pues no alteran el sentido de la escena. Ambos se besan y hacen el amor como si fuera el último día de sus vidas. Nada es más importante en ese momento. No hay palabras. El resto quedará para ser interpretado por los actores, bajo la dirección de primer destinatario del texto: el director. En su trabajo quedará plasmada la comprensión del sentido de la escena. El casting hará lo suyo, aunque correctamente dirigidos, la pareja de actores no debiera sorprender, solo ejecutar las concordancias y llenando los vacíos. Es decir, traducir, manteniendo intacto el sentido. Podría decirse que la traducción literal, en lo que atañe a la sintaxis, impide por completo la reproducción del sentido y amenaza con desembocar directamente en la incomprensión. 
Al respecto, Benjamin nos dice que "es preferible que la traducción, en vez de identificarse con el sentido del original, reconstituya hasta en los menores detalles el pensamiento de aquél en su propio idioma, para que ambos, del mismo modo que los trozos, de la vasija, puedan reconocerse como fragmentos de un lenguaje superior [...] La verdadera traducción es transparente, no cubre el original, no le hace sombra, sino que deja caer en toda su plenitud sobre éste el lenguaje puro, como fortalecido por su mediación" (1971:139).

Esto es posible porque, por importante que sea la parte de comunicación que se extraiga del guion (y que se traduzca), siempre permanecerá intangible la parte que persigue el trabajo del auténtico traductor (el realizador, el actor). Ésta no es transmisible, como sucede con la palabra del autor en el primer texto, porque la relación entre su esencia y el lenguaje es totalmente distinta en el original y en la traducción. Si, como dice Benjamin, en todas las lenguas y en sus formas, además de lo transmisible, queda algo imposible de transmitir, el guionista como primer traductor de su propia creación es consciente de que lo simbolizado es regulado por el contexto en el cual escribe. Lo no transmitible adquiere la forma de un simbolizante que toma una forma distinta según el devenir de la experiencia y biografía del segundo traductor. Por todo esto, el guion no puede ser concebido como literatura filmada o dibujada. Es un relato que le pone rostros a las cosas.

\section{Conclusión}

En el guion, ¿qué se traduce entonces? Lo que se traduce es el sentido de la ensoñación, no la palabra escrita. Se apela, por tanto, a la comprensión de la idea, no la mantención de la textura del lenguaje. Como en ambos códigos -el original y el nuevo- hay vacíos interpretativos que llenar, el traductor hace uso de ese recurso, que provoca un tercer texto que sería el portador del sentido idéntico entre el primero y el segundo. El vacío de ambos produce el milagro: se logra la traducción.

¿Se puede hablar de grados de traductibilidad en un guion? Sí. Depende de la profundidad o superficialidad que logre el sentido del texto original. Ello es determinante para el éxito de la traducción, dado que éstas envejecen, como postula Umberto Eco. Las traducciones mejoran con el tiempo. Se adecuan a necesidades interpretativas.

Un texto que se deja traducir entrega, entonces, amplias posibilidades para posteriores análisis hermenéuticos. Es un texto abierto, como el guion, que asume en su origen, la permanente posibilidad de que se le añadan nuevas y actualizadas traducciones, llevando el original a las versiones más osadas, bajo el amparo de las nuevas audiencias o recursos estéticos de los lenguajes no escritos. Quizás, se cumple la lógica de lo que formula Jorge Santiago Perednik en Ensayos sobre la traducción, cuando indica que los mejores traductores logran lo que la obra de arte: encontrar ante una imposibilidad una salida deslumbrante que no la resuelve.

La literatura depende de las posibilidades múltiples del texto, de la zona donde las palabras derrotan su significado corriente, razón por la que el lenguaje literario garantiza que la obra pase sin pérdida a otro idioma. El guion nunca pierde. Siempre gana en actualización de sentido. Pierde en literalidad (y con ello algo queda en el camino), pues no está concebido para tanta fidelidad. Es la diferencia de nacer para morir como texto, pues deja vivir el núcleo en el tejido de otro lenguaje. Siguiendo a Benjamin, la traducción no corresponde a la vida del original, pues el original ya está muerto, sino que la traducción pertenece a la otra vida del original, confirmando, así, la muerte de éste. 
Podríamos resumir este ensayo con la fecunda tarea del guionista-traductor: develar las oscuras palabras del texto primero, quien fallece, en favor del texto segundo y de todos los que vendrán.

\section{Nota}

Este texto surge en el marco del Proyecto FONDECYT №1160637, titulado "La formación del guionista en Chile: análisis de los enfoques curriculares y modelos de evaluación de la escritura para cine, televisión y transmedia", financiado por la Comisión Nacional de Investigación Científica y Tecnológica de Chile (CONICYT), y del cual el autor es investigador responsable.

\section{Bibliografía}

Benjamin, W. 1971. La obra de arte en la era de su reproductibilidad técnica y otros textos. Buenos Aires: Godot.

Castoriadis, C. 1998. Hecho y por hacer. Pensar la imaginación. Buenos Aires: Eudeba.

Detienne, M. 2001. Comparar lo incomparable. Barcelona: Península.

Dittus, R. 2017. El guionista chileno: análisis cuantitativo sobre el oficio de escribir para cine. Cuadernos.Info 41: 193-207. https://doi.org/10.7764/cdi.41.1139

Durand, G. 2000. La imaginación simbólica. Buenos Aires: Amorrortu.

Eco, U. 2010. Decir casi lo mismo. Buenos Aires: Lumen.

Metz, C. 2002. Ensayos sobre la significación en el cine (1964-1968). Barcelona: Paidós.

Morin, E. 2001. El cine o el hombre imaginario. Barcelona: Paidós.

Reyes, A. 1983. De la traducción. Ciudad de México: Fondo de Cultura Económica.

Ricoeur, P. 2005. Sobre la traducción. Buenos Aires: Paidós.

Sironi, G. 2015. El viento de la derrota. A propósito de la traducción. Calibán 13(3): 153-154. http://www.fepal.org/revista caliban bivipsil/13 caliban castp.pdf

Tarkovski, A. 2017. Atrapad la vida. Madrid: Errata Naturae.

Recibido el 25 Oct 2018

Aceptado el 26 Dic 2018 